Document donwnloaded from:

[http://redivia.gva.es/handle/20.500.11939/6451]

This paper must be cited as:

[Visconti, F., \& de Paz, J. M. (2019). Non-destructive assessment of chloride in persimmon leaves using a miniature visible near-infrared spectrometer. Computers and Electronics in Agriculture, 164, 104894.]

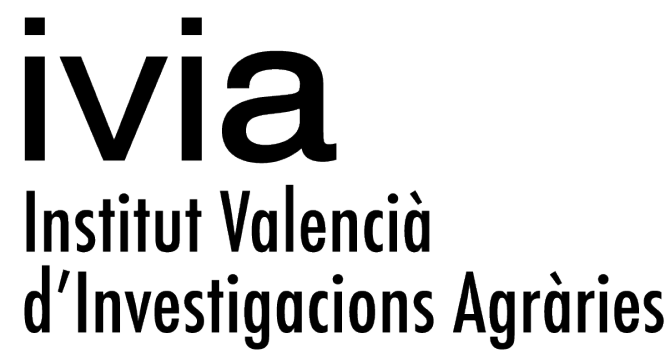

The final publication is available at

[http://dx.doi.org/10.1016/j.compag.2019.104894]

Copyright [Elsevier] 


\section{Non-destructive assessment of chloride in persimmon leaves using a 2 miniature visible near-infrared spectrometer}

3 Fernando Visconti*, José Miguel de Paz

4 Instituto Valenciano de Investigaciones Agrarias-IVIA (GV), Centro para el Desarrollo de la

5 Agricultura Sostenible-CDAS, Carretera CV-315, Km 10.7, 46113 Moncada, València, Spain.

6

7

8

*Corresponding author (F. Visconti): visconti_fer@gva.es

Abstract

New methods for the non-destructive, rapid and reliable assessment of leaf chloride $\left(\mathrm{Cl}^{-}\right)$are needed in many agricultural salt-threatened areas throughout the World. Although portable visible near-infrared spectrometers could be useful for this task, accompanying models for leaf $\mathrm{Cl}^{-}$assessment on basis their visible near-infrared (Vis-NIR) spectra had yet to be developed. To study the feasibility of such models, a persimmon orchard was grown in E Spain and irrigated with eight waters ranging in $\mathrm{Cl}^{-}$concentration from 70 to $350 \mathrm{mg} / \mathrm{L}$. Then, six times throughout the growing season the Vis-NIR foliar reflectance spectra of various representative leaves per $\mathrm{Cl}^{-}$treatment were recorded with a portable miniature Vis-NIR spectrometer. The leaf $\mathrm{Cl}^{-}$was subsequently determined in the same leaves with a laboratory reference method. Next, both the $\mathrm{Cl}^{-}$and spectral data were analyzed using descriptive statistics, mathematical data transformations, principal components analysis (PCA) and partial least squares regression (PLSR). A wide, sufficiently normal-distributed and representative range of leaf $\mathrm{Cl}^{-}$content from 0.17 to $3.14 \% \mathrm{Cl}^{-}$was obtained. With correlation coefficients exceeding +0.65 between 390 and $472 \mathrm{~nm}$ and between 690 and $692 \mathrm{~nm}$, the foliar reflectance was the spectral data correlated the most with the leaf $\mathrm{Cl}^{-}$. Remarkably, both wavelengths intervals are where chlorophyll a has its two absorbance maxima in the visible region. A PLSR model including all the wavelengths in the Vis-NIR reflectance spectra plus the day of the year, attained values of $\mathrm{R}^{2}=0.78, \mathrm{RMSE}=0.34 \% \mathrm{Cl}^{-}$and $\mathrm{RPD}=2.18$ in the external validation. However, for leaf $\mathrm{Cl}^{-}$ below $1.5 \% \mathrm{Cl}^{-}$, i.e., when $\mathrm{Cl}^{-}$assessment is most needed, this model presented $\mathrm{R}^{2}=0.55$, but RMSE $=0.08 \% \mathrm{Cl}^{-}$and $\mathrm{RPD}=5.5$, in addition to a bias of $+0.04 \% \mathrm{Cl}^{-}$and a standard error of $0.05 \% \mathrm{Cl}^{-}$. These results show that portable Vis-NIR spectrometers can be useful for the nondestructive, rapid and even reliable assessment of leaf $\mathrm{Cl}^{-}$. The potential of this methodology for other crop plants and inorganic ions should be tested.

Keywords: Chloride, Chemometrics, Visible-NIR spectroscopy, Persimmon, Partial least squares 
Abbreviations:

34

A: Apparent absorbance

35

$\mathrm{d} A / \mathrm{d} \lambda$ : First derivative of the apparent absorbance

$36 \mathrm{~d}^{2} A / \mathrm{d} \lambda^{2}$ : Second derivative of the apparent absorbance

$37 \mathrm{Cl}^{-}$: Chloride

38 Chl $a$ : Chlorophyll a

39 Chl $b$ : Chlorophyll b

40 DOY: Day of the year

41 DW: Dry weight

42 K-S: Kolmogorov-Smirnov

43 LC: Latent component

44 LNC: Leaf nitrogen content

$45 \lambda$ : wavelength

46 MLR: Multiple linear regression

47 NIR: Near-infrared

48 PC: Principal component

49 PCA: Principal components analysis

50 PCR: Principal components regression

51 PLSR: Partial least squares regression

$52 \mathrm{R}^{2}$ : Coefficient of determination

$53 \quad R$ : Foliar reflectance

54 RMSE: Root mean square error

55 RPD: Ratio of standard error of performance to standard deviation

56 SLSR: Simple least squares regression

57 Vis-NIR: Visible near-infrared

58

\section{Introduction}

60 Chlorine has been long considered as an essential plant nutrient (Broyer et al., 1954). It occurs

61 as chloride $\left(\mathrm{Cl}^{-}\right)$in plants and, because it readily moves in the sap stream from roots to shoots,

62 but not so much in the other way round, tends to accumulate in leaves and fruits (White and

63 Broadley, 2001; Raveh, 2005; Li et al., 2017). Chloride functions in plants are diverse: counter

64 ion for cations, unspecific osmoticum for turgor maintenance, proton-transferring in

65 photosystem II, stomata opening and closure, etc. (Guskov et al., 2009; Raven, 2017). Chloride

66 contents of $0.02-0.2 \%$ (DW) are usually enough to fulfil these functions in most plants, i.e.,

67 non-halophytes, e.g., all crops (Marschner, 2011). However, under certain conditions crops 
accumulate $\mathrm{Cl}^{-}$in their leaves up to $1.5-5 \%$ (Xu et al., 2000). Excess leaf $\mathrm{Cl}^{-}$harms photosynthetic activity in several ways (Geilfus, 2018) and, although plants buffer cytosolic $\mathrm{Cl}^{-}$ concentration by pumping this ion into cell vacuoles through transport proteins ( $\mathrm{Li}$ et al., 2017; Geilfus, 2018), this process requires energy and thus, inevitably, crop growth and development become impaired. This is an effect of phytotoxicity, which often progresses unnoticed and, when it finally shows up as leaf chlorosis and even necrosis, is much too late to avoid yield losses and other damages (Geilfus, 2018). In many agricultural areas under dry subhumid to arid climates, such as the persimmon plantations in Valencia (E Spain), $\mathrm{Cl}^{-}$phytotoxicity is an important agronomical problem (Visconti et al., 2017), and early information about leaf $\mathrm{Cl}^{-}$ contents is needed to take measures and reduce harms.

The usual $\mathrm{Cl}^{-}$assessment in plant leaves is done by means of a destructive laboratory timeconsuming wet analysis (Miller, 1998) and, although quicker methods such as those using NIR bench spectrometers in conjunction with partial least squares regression (PLSR) have been developed (de Paz et al., 2016), new faster procedures would be welcome. At this point, portable leaf spectrometers could offer the basis for such methods. Portable leaf spectrometers for agricultural use span from simple devices using very few wavelengths in the visible region to full-range visible near-infrared (Vis-NIR) spectrometers. This kind of equipment is increasingly used for the rapid appraisal of plant nutrient status, mostly for the indirect estimation of leaf nitrogen content (LNC) through the measurement of leaf transmittance, reflectance and/or fluorescence properties (Padilla et al., 2018; Ali et al., 2017), however, their ability for other element estimations is yet to be explored.

Elements such as chlorine, which are mostly present as free hydrated ions in plants, are by themselves spectroscopically inactive in the whole Vis-NIR range (Shao et al., 2012). Therefore, their detection and eventual quantification using Vis-NIR radiation, has to be done taking advantage of their biochemical and physicochemical effects on the spectroscopicallyactive compounds present in plants. These can be either pigments, such as chlorophylls, carotenoids and flavonoids, in the case of the visible radiation and, additionally, many other colorless organic compounds in the case of the near-infrared (van Maarschalkerweerd et al., 2013). In the NIR region, hydrogen bonding of $\mathrm{Cl}^{-}$to peptide bonds in proteins $\left(>\mathrm{N}-\mathrm{H}^{\cdots} \mathrm{Cl}^{-}\right)$ was identified as the foundation for $\mathrm{Cl}^{-}$assessment in dry leaves with excellent coefficients of determination (de Paz et al., 2016). In fresh leaves, however, the plentiful of water molecules are expected to get $\mathrm{Cl}^{-}$away from most peptide groups in proteins and, therefore, the ability of NIR spectroscopy for $\mathrm{Cl}^{-}$assessment in this material is deduced to be much weaker. Regarding the leaf water content, its interference is general in LNC estimation with Vis-NIR spectrometers (Samborski et al., 2009). On the contrary, with regard to visible radiation, it has been suggested 
that $\mathrm{Cl}^{-}$could facilitate chlorophyll degradation (Geilfus, 2018), thus providing an important biochemical effect for revealing itself in the leaf visible spectrum.

In order to use all the possible effects of $\mathrm{Cl}^{-}$on the Vis-NIR leaf spectrum for its assessment without sample destruction, chemometric techniques such as PLSR are the most promising. This is due to the ability of PLSR to optimally take advantage of the whole available spectral information in the range of interest without being hampered neither by the high number of predictive variables, i.e. the wavelengths, nor by the collinearities amongst them. Based on all the predictive variables, PLSR builds several linear functions, or latent components (LCs), that are uncorrelated amongst them and, simultaneously maximize covariance with the analyte of interest (Abdi, 2007), thus overcoming the limitations of multiple linear regression (MLR) models (Tobias, 2003). Furthermore, the performance of PLSR models can be improved by means of data transformations such as derivation, mean-centering and others. All of them increase the signal-to-noise ratio, thus revealing the minute effects on spectra of otherwise difficult-to-detect analytes (Zhang et al., 2019).

Therefore, the objective of this investigation was to study the ability of a portable miniature visible near-infrared spectrometer for the non-destructive assessment of $\mathrm{Cl}^{-}$in plant leaves. Specifically, this study was performed on persimmon (Diospyros kaki L.) using PLSR.

\section{Materials and methods}

\subsection{Experimental persimmon orchard}

In 2016 a persimmon orchard was established in the IVIA Agricultural Experimental Station in Moncada (València, Spain) by planting in soil of 48 five-year-old trees of Diospyros kaki grafted on Diospyros lotus scions. In order to have both the development and wide range of leaf $\mathrm{Cl}^{-}$contents reported for the commercial persimmon plantations in the Valencia cropping area, the 48 trees were, on the one hand, equally fertilized, and, on the other hand, exposed to different $\mathrm{Cl}^{-}$water contents by spliting them into eight groups or $\mathrm{Cl}^{-}$treatments. Therefore, during the growth seasons from April to October of 2016 and 2017, each treatment was irrigated with a different synthetic solution made by dissolving in desalinated water of the same amounts of mineral fertilizers $\left(\mathrm{KNO}_{3}, \mathrm{Ca}\left(\mathrm{NO}_{3}\right)_{2}, \mathrm{MgSO}_{4} \cdot 7 \mathrm{H}_{2} \mathrm{O}, \mathrm{H}_{3} \mathrm{PO}_{4} 75 \%\right.$, Fe-EDDHA, $\mathrm{H}_{3} \mathrm{BO}_{3}$, $\mathrm{ZnSO}_{4}, \mathrm{MnSO}_{4}$, and $\mathrm{H}_{2} \mathrm{MoO}_{4}$ ) and increasing amounts of $\mathrm{NaCl}$ and $\mathrm{CaCl}_{2}$ so as to obtain $8 \mathrm{Cl}^{-}$ water concentrations between 70 and $350 \mathrm{mg} / \mathrm{L}$ separated by a constant increment of $40 \mathrm{mg} / \mathrm{L}$.

\subsection{Leaf sampling}


134 Six times throughout the growing season of 2017 several leaves from each treatment were cut 135 and joined into composite samples. The cuttings were done in May $4^{\text {th }}$, June $1^{\text {st }}$, June $27^{\text {th }}$, 136 August $2^{\text {nd }}$, September $12^{\text {th }}$ and October $30^{\text {th }}$. In the first five samplings 20 leaves per treatment 137 were collected, whereas in the last sampling 20 leaves were also collected, but from each tree 138 instead. This way we tried to increase the number of samples high in $\mathrm{Cl}^{-}$since we knew that $\mathrm{Cl}^{-}$ 139 accumulates throughout the growing season (Visconti et al., 2017). Therefore, we had 8 140 treatments $\times(5$ samplings $\times 1$ sample per treatment +1 sampling $\times 1$ sample per tree $\times 6$ trees 141 per treatment) -5 lost samples $=83$ leaf samples. These lost leaf samples were from trees 142 severely damaged. The leaves were randomly selected amongst those fully extended, usually the 143 third one from the tip of as many different shoots as possible. Once collected, the leaves were 144 immediately sealed in plastic bags and carried to the laboratory at air temperature since the 145 experimental field was just $250 \mathrm{~m}$ distant.

\section{2.3. Spectral measurements of the leaves}

147 Once in the laboratory the foliar reflectance $(R)$ from the upper side of the leaves between 345 148 and $1040 \mathrm{~nm}$ was recorded. In the first five samplings six leaves randomly selected from each treatment were measured, whereas in the last sampling six leaves also randomly chosen, but this

150 time from each tree, were measured. A place to the left of the leaf midrib between the second 151 and third vein was selected for measurement.

152 The CI-710 Miniature Leaf Spectrometer (CID Bio-Science, Inc., Camas, Washington, USA) 153 was used to record the $R$ spectra. This fully portable spectrometer is able to measure the Vis154 NIR transmittance, absorbance or reflectance spectrum between 345 and $1050 \mathrm{~nm}$ of a leaf area 155 just $6 \mathrm{~mm}^{2}$. Its radiation source combines a blue LED and an incandescent lamp and a clip 156 system protects the measurement area from the interference of the environmental light. 157 Adjusting the measurement specifications of i) number of average scans per recorded spectrum, 158 ii) integration time and iii) boxcar width, the user can smooth the spectra and maximize the 159 signal-to-noise ratio (CID Bio-Science, 2013). For these parameters several values were tried in 160 the first leaves, and the most adequate were found to be, respectively, 4, $400 \mathrm{~ms}$ and 10 . Then, these values were systematically used for all the $R$ measurements.

\subsection{Reference leaf chloride contents}

163 Following the $R$ measurements all the leaves from the same treatment (first five samplings) or 164 the same tree (last sampling) were gathered for $\mathrm{Cl}^{-}$determination following the reference 165 method of Miller (1998). The sample pretreatment included washing with a nonionic detergent solution and then rinsing with deionised water. Next, the leaves were frozen into liquid nitrogen, 

refrigerated mill (IKA M 20, IKA Labortechnik, Staufen, Germany). Next, half a gram of the dry and grounded leaf material was shaked in $40 \mathrm{~mL}$ of $2 \%$ acetic acid for $24 \mathrm{~h}$ (Gilliam, 1971), and the $\mathrm{Cl}^{-}$concentration in this extract was determined by argentometry using a coulometricamperometric titration (Cotlove, 1963) by means of the Chloride Analyser 926 (Corning Ltd., Halstead, Essex, UK). Finally, the $\mathrm{Cl}^{-}$contents were expressed on a dry weight base.

\subsection{Processing of the spectral data of the leaves}

The foliar reflectance $(R)$ spectra were summed up to have 251 equally spaced data per spectrum within a narrower interval from 380 to $1000 \mathrm{~nm}$. This was done by linear interpolation of the reflectance value at the new wavelengths of $380 \mathrm{~nm}, 382.48 \mathrm{~nm}, 384.96 \mathrm{~nm}$, etc., until $1000 \mathrm{~nm}$, using the two immediate lower and higher old wavelengths to each of these new ones. Then, the $R$ spectra from the same treatment (first five samplings) or the same tree (last sampling) were averaged to have, respectively, one mean spectrum per treatment or tree. In the following step, the absorbance $(A)$ was calculated from the foliar reflectance according to the formula $A=-\log R$, and then, the first and second derivatives of the absorbance were calculated using equations 1 and 2 :

$\left.\frac{\mathrm{d} A}{\mathrm{~d} \lambda}\right|_{\left(\lambda_{m+1}-\lambda_{m}\right) / 2}=\frac{A_{m+1}-A_{m}}{\lambda_{m+1}-\lambda_{m}}$

$$
\left.\frac{\mathrm{d}^{2} A}{\mathrm{~d} \lambda^{2}}\right|_{\left(\lambda_{m+1}-\lambda_{m}\right) / 2}=\frac{\left.\frac{d A}{d \lambda}\right|_{m+1}-\left.\frac{d A}{d \lambda}\right|_{m}}{\lambda_{m+1}-\lambda_{m}}
$$

where $\lambda$ is the wavelength, and $m$ indicates the order from the first to the last wavelength.

Several exploratory data analyses were carried out with the aid of the R packages 'stats', 'moments' and 'nortest' which were built under R software versions, respectively, 3.5.1, 3.5.2 and 3.5.2 (R Core Team, 2018). First of all, the distribution of the $\mathrm{Cl}^{-}$contents in the leaves was studied by assessing skewness with the Pearson's moment coefficient, and normality with the Kolmogorov-Smirnov and Lilliefors tests. Additionally, the Pearson's product-moment correlation coefficients between $\mathrm{Cl}^{-}$contents and the spectral datasets, throughout the interval from 380 to $1000 \mathrm{~nm}$ were calculated. Finally, the principal components analyses (PCAs) of the matrix of correlation coefficients between, respectively, $R, A, \mathrm{~d} A / \mathrm{d} \lambda$ and $\mathrm{d}^{2} A / \mathrm{d} \lambda^{2}$ at each wavelength were done. The maximum number of PCs with eigenvalue over 1 was taken into account for the ensuing model developments with PLSR. 
The 83 rows of $\mathrm{Cl}^{-}$content plus spectral data were split into one training set made up of $3 / 4$ of the rows, i.e. 62 rows, and one testing set made up of $1 / 4$ of the rows, i.e. 21 rows. The splitting was done by systematically assigning the $(4 i+3)^{\text {th }}$ row of data, where $i$ is equal to $0,1,2$, etc., to the testing set and the remaining rows to the training set. The training set was used for the model calibrations and leave-one-out cross-validations. First of all, simple least squares regression using the wavelength of maximum correlation with leaf $\mathrm{Cl}^{-}$content was applied to obtain a basic benchmark model for subsequent comparisons. Next, the spectral data were mean centered given mean-centering improves modeling because it helps to reduce multicollinearity between predictive variables (Marquardt, 1980). Then, partial least squares regression (PLSR) was used to develop various predictive models differing in their number of LCs. The calibrations and cross-validations of PLSR models were done with the software ParLeS (Viscarra Rossel, 2008).

\subsection{External validation of the PLSR model}

The selected PLSR models were additionally subjected to an external validation through prediction of the $\mathrm{Cl}^{-}$contents in the leaves of the testing set and comparison with the reference contents.

\section{Results and discussion}

\subsection{Chloride contents in the leaves}

The leaf $\mathrm{Cl}^{-}$increased throughout time during the growing season, i.e. with the day of the year (DOY), in all treatments (Fig. 1), and from a minimum of 0.17 up to a maximum of $3.14 \% \mathrm{Cl}^{-}$ (Table 1). These extreme values in addition to a mean of $1.30 \% \mathrm{Cl}^{-}$compare well to the leaf $\mathrm{Cl}^{-}$ contents found in many commercial persimmon plantations in the Valencia cropping area. In the training set the $\mathrm{Cl}^{-}$contents were between 0.17 and $3.14 \%$ with mean of $1.29 \%$, while in the testing set were between 0.22 and $3.05 \%$ with mean of $1.33 \%$.

\section{[Figure 1]}

Concerning the leaf $\mathrm{Cl}^{-}$statistical distribution, it exhibited a positively skewed one that, however, did not significantly depart from normality according to the Kolmogorov-Smirnov test, and not even with the more demanding Lilliefors test (Table 1). As a consequence, although somewhat skewed, the $\mathrm{Cl}^{-}$data could be regarded as to come from a normal-distributed population.

[Table 1]

\subsection{Visible Near-infrared spectra}


The Vis-NIR foliar reflectance and absorbance spectra of all leaf samples along with the first and second derivatives of the absorbance are shown in Fig. 2.

231 The correlation coefficients $(r)$ between leaf $\mathrm{Cl}^{-}$and foliar reflectance were between 0.05 and

2320.77 with up to 37 wavelengths remarkably correlated, i.e., with $r$ in absolute value exceeding 2330.65 (Fig. 3 and Table 2). The correlation coefficients with absorbance reversed, however. 234 Besides, both the maximum in absolute value and the number of remarkably correlated wavelengths decreased to, respectively, 0.66 and 11 . First derivation recovered the maximum correlation with $\mathrm{Cl}^{-}$content but lost wavelengths with $|r|$ over 0.65 , whereas an additional derivation worsened correlations even more.

[Figure 3]

240 The maximum correlation in absolute value of foliar reflectance with $\mathrm{Cl}^{-}$content occurred at $241412 \mathrm{~nm}$. The other wavelengths with remarkable correlation coefficients in absolute value were 242 all in the visible region: between 390 and 472, 626, 643 and between 690 and $692 \mathrm{~nm}$, whereas 243 in the NIR, i.e., between 700 and $1000 \mathrm{~nm}$, none appeared. The leaf chlorophylls, i.e., Chl $a$ and

$244 \mathrm{Chl} b$, and additionally, other important pigments such as $\beta$-carotene, absorb light in the visible 245 range where they present several absorbance maxima, remarkably between 400 and $500 \mathrm{~nm}$ and 246 between 650 and $700 \mathrm{~nm}$ (Fig. 4). Since the maximum correlation of leaf $\mathrm{Cl}^{-}$as shown in Fig. 3 247 matches the two wavelengths intervals of maximum absorbance by Chl $a$ (Fig. 4), it seems that $248 \mathrm{Cl}^{-}$interacts specifically with $\mathrm{Chl} a$ to show up in the leaf spectra. Moreover, given that its 249 correlation with foliar reflectance is positive, then $\mathrm{Cl}^{-}$acts by decreasing either Chl $a$ content or 250 its light absorption. Romero et al. (1997) found that the contents of chlorophylls in melon leaves 251 decreased as a consequence of $\mathrm{Cl}^{-}$, thus the same biochemical degradative effect likely occurs in our persimmon leaves.

\section{3 [Figure 4]}

254 These results obtained for the Vis-NIR region up to $1000 \mathrm{~nm}$ complement those attained by de Paz et al. (2016), who found that $\mathrm{Cl}^{-}$interaction with peptide bonds changes the leaf NIR spectrum between 1200 and $2400 \mathrm{~nm}$. In the NIR region between 1200 and $2400 \mathrm{~nm}$, however, the effects of $\mathrm{Cl}^{-}$were only clearly seen in the first derivative of the absorbance, thus they changed the steepness of the absorbance maxima and minima there. Conversely, in the case of the Vis-NIR region between 380 and $1000 \mathrm{~nm}$ analyzed in this work, the interaction of $\mathrm{Cl}^{-}$with 
the leaf organic compounds mainly changes the magnitude of their absorbance and, hence, the foliar reflectance. Therefore, the $\mathrm{Cl}^{-}$effects in the leaf visible spectrum are stronger than in the NIR one and thus, foliar reflectance itself is the most adequate property for $\mathrm{Cl}^{-}$prediction using Vis-NIR spectroscopy. The foliar reflectance was thus selected for modeling.

\subsection{Principal components analyses}

In the foliar reflectance spectrum up to 6 principal components (PCs) had eigenvalues exceeding one, and these jointly accounted for $99.5 \%$ of variance. The DOY was included along with the foliar reflectance spectrum, however, this barely changed the amount of variance explained by the six first PCs, and it neither changed the number of PCs with eigenvalue over unity. This high amount of variance explained by so few PCs reveals, firstly, that there are important collinearities amongst all the wavelengths in the foliar reflectance and, secondly, that DOY is also highly correlated with all these wavelengths. In spite of this high correlation, DOY could still provide important predictive information because of the evolution of foliar reflectance throughout the growing season, which is what DOY measures and thus, DOY could be profitably added into a PLSR model.

\subsection{Partial least squares regressions}

In the first place and for the sake of parsimony, a simple least squares regression (SLSR) was carried out using the foliar reflectance wavelength in the training set that featured the maximum correlation with leaf $\mathrm{Cl}^{-}$. This was $412 \mathrm{~nm}$ (Figure 3 and Table 2). According to the leave-oneout cross-validation used to test this SLSR model, the following values for the fit parameters were obtained: $\mathrm{R}^{2}=0.548$, RMSE $=0.541 \% \mathrm{Cl}^{-}$and $\mathrm{RPD}=1.498$. This model could be improved by including more variables, such as other wavelengths and even DOY following an MLR approach. However, as the previous PCA revealed, all the wavelengths in the reflectance spectrum are highly correlated amongst them and, additionally, with DOY. This fact would lead to an MLR model with regression coefficients severely inflated in variance, i.e., unstable and, definitely, to a potentially misleading model (Gunst, 1983). In such a case of multicollinearity the best alternative for model development is PCR or PLSR. However, given that PLSR is particularly adequate when, in addition to multicollinearity, there are more predictive variables than cases (Wold et al., 2001; Abdi, 2007), as happens in this investigation, PLSR was selected.

291 Since 6 was the number of PCs with eigenvalues over one, PLSR was applied to develop up to 6 $\times 2=12$ models by using, on the one hand, all the wavelengths with foliar reflectance data and, 
various models with between 6 and 12 LCs are shown. As the number of LCs increased, the $\mathrm{R}^{2}$ also increased until 9 LCs without DOY and until 8 LCs with DOY. The assessment of RPD complements the interpretation of $\mathrm{R}^{2}$, and it is shown that the RPD kept under 1.75 for models without DOY and over 1.75 for models using DOY. Again, the RMSE only presented values below $0.47 \% \mathrm{Cl}^{-}$for the models using DOY. On average the $\mathrm{R}^{2}$, RMSE and RPD were, respectively, 0.05 higher, $0.04 \% \mathrm{Cl}^{-}$lower and 0.15 higher for the models using DOY. The fit between predictions and observations in the training dataset can be visually appreciated to the left of Fig. 5.

302

[Figure 6]

The enhanced fit between leaf $\mathrm{Cl}^{-}$predictions and observations caused by the inclusion of DOY in the PLSR model development confirms that, on its own, elapsed time throughout the cropping season influences leaf spectra. Therefore, the inclusion of DOY in the model would take into account the variation that time throughout the season contributes to reflectance and, thus, would contribute to isolate the effect of just $\mathrm{Cl}^{-}$.

The DOY was, therefore, included in the model. In Fig. 6 it is graphically explained how DOY influences the foliar reflectance through two different effects: one direct and another indirect by means of $\mathrm{Cl}^{-}$. On the one hand, the leaf chlorophyll contents change throughout the growing season, i.e. as DOY increases (Hörtensteiner and Kräutler, 2011). On the other hand, in the case of trees subjected to $\mathrm{Cl}^{-}$, the leaf content of this anion also increases throughout the growing season, i.e. as DOY increases, as it occurred in our persimmon orchard (Fig. 1). Since excess $\mathrm{Cl}^{-}$ likely eases chlorophyll, specifically $\mathrm{Chl} a$, degradation, leaf reflectance also indirectly changes, particularly decreases, with time as a consequence of $\mathrm{Cl}^{-}$increase.

[Table 3]

\section{7 [Figure 5]}

\subsection{External validation of the PLSR models}

All the models built in the previous calibration were used in the testing dataset and observations were compared with predictions by means of the fit parameters R $^{2}$, RMSE and RPD (Table 3 ) in addition to a graph (Fig. 5 right). The $\mathrm{R}^{2}$ reached values over 0.75 for several models either using or not using DOY. Besides, RPD overcame 2 and RMSE dropped below 0.4 for almost the same models. Taking into account both the cross- and the external validations, the model using DOY plus all the wavelengths in the foliar reflectance spectra and, then, 8 LCs was the selected one. This model has been highlighted in italics in Table 3, and the fit between model 
predictions and reference leaf $\mathrm{Cl}^{-}$contents in the training and testing datasets can be visually appreciated in Fig 4. For the benefit of the reader, the regression coefficients, loading weights and spectral LC loadings of this model have been provided as Electronic Supplementary Material (ESM) in the form of a spreadsheet. According to the plots of residuals in the training dataset, the errors of the selected PLSR model can be regarded as normally-distributed, however, they slightly increase with $\mathrm{Cl}^{-}$content (Fig. 7).

\section{[Figure 7]}

The RPD values featuring the selected model both in calibration and validation were well below 3 indicating that the selected model could be regarded as acceptable for estimation but not for determination purposes (Fearn, 2002). This RPD values contrast with the ones obtained for leaf $\mathrm{Cl}^{-}$assessment using dry and grounded leaves and the NIR absorbance first derivative between 1200 and $2400 \mathrm{~nm}$ (de Paz et al., 2016), which in that instance were over 4.5 in cross-validation and 3.5 in external validation for the whole $0-3 \% \mathrm{Cl}^{-}$range. In the present research, nevertheless, two zones separated by $1.5 \% \mathrm{Cl}^{-}$can still be distinguished in the residuals plot (Fig. 7) and, the lower one better adapted for prediction purposes. In this area of less than 1.5 $\% \mathrm{Cl}^{-}$, RMSE drops to $0.08 \% \mathrm{Cl}^{-}$and $\mathrm{RPD}$ reaches 5.5. It is interesting to note that for $\mathrm{Cl}^{-}$ contents over $1.3 \% \mathrm{Cl}^{-}$, leaf burn inevitably shows up in persimmons, i.e., it becomes visible (Visconti et al., 2017). It is, therefore, for low leaf $\mathrm{Cl}^{-}$contents $\left(<1.3 \% \mathrm{Cl}^{-}\right)$for which predictions are most needed. Given that below $1.3 \% \mathrm{Cl}^{-}$is when the selected model better fulfils the requirements for prediction, it is worth using at least there. In this zone of low $\mathrm{Cl}^{-}$content, the method standard error is $0.05 \% \mathrm{Cl}^{-}$. This is seven times more than the reference method and almost double than the laboratory method based on NIR that was developed by de Paz et al. (2016). Besides, the method presented here has a bias of just $+0.04 \% \mathrm{Cl}^{-}$, i.e., it barely overestimates $\mathrm{Cl}^{-}$content on average.

\section{Conclusions}

The $\mathrm{Cl}^{-}$contents in persimmon leaves were found to be remarkably and positively correlated with the foliar reflectance between 390 and 472 and between 690 and $692 \mathrm{~nm}$. Both wavelength intervals correspond to the two absorption maxima $\mathrm{Chl} a$ has in the visible region. These high correlations point to the fact that $\mathrm{Cl}^{-}$interacts with this key leaf pigment, maybe easing its degradation, and thus making it possible to use Vis-NIR spectroscopy for the assessment of this otherwise Vis-NIR inactive anion. Notwithstanding this, since leaf chlorophylls also naturally evolve throughout the growing season, an additional time variable, i.e., DOY, had to be included in order to refine a predictive model for leaf $\mathrm{Cl}^{-}$. According to the cross-validation and subsequent external validation, the adequate number of latent factors to be included in such a 
model based on PLSR, was 8. This model had a $\mathrm{R}^{2}$ of 0.78 , a RMSE of $0.34 \% \mathrm{Cl}^{-}$and a RPD of 2.18. Besides, although for leaf $\mathrm{Cl}^{-}$contents below $1.5 \% \mathrm{Cl}^{-}$this model presents $\mathrm{R}^{2}$ of 0.55 , its performance improves in terms of RMSE $\left(0.08 \% \mathrm{Cl}^{-}\right)$, and RPD (5.5). Additionally, with bias of $+0.04 \% \mathrm{Cl}^{-}$and standard error of $0.05 \% \mathrm{Cl}^{-}$this PLSR model is barely affected by systematic errors, though has a standard error seven times the reference laboratory wet method. This latter fact increases the relative standard deviation of this leaf $\mathrm{Cl}^{-}$assessment method to $20 \%$. In conclusion, the use of portable Vis-NIR spectrometers in conjunction with PLSR models can be recommended for the non-destructive, rapid and, at least under $1.5 \% \mathrm{Cl}^{-}$, even reliable assessment of leaf $\mathrm{Cl}^{-}$in persimmon orchards. The potential of this methodology for other crop plants and inorganic ions should be tested.

\section{Acknowledgements}

The purchase of the miniature leaf spectrometer CI-710 was supported by the European Regional Development Fund Valencian Community 2014 - 2020 [actuation line 010102_03]. We would like to thank the editor and the two anonymous reviewers for their comments and indications which improved the article.

\section{Declarations of interest}

On behalf of all authors, the corresponding author states that there is no conflict of interest.

\section{References}

Abdi, H. 2007. Partial least square regression (PLS regression). In: Salkind, N. J. (ed.), Encyclopedia of Measurement and Statistics. Thousand Oaks (CA): Sage.

Ali, M.M., Al-Ani, A., Eamus, D., Tan, D.K.Y., 2017. Leaf Nitrogen Determination Using NonDestructive Techniques - A Review. Journal of Plant Nutrition 40 (7), 928-953. doi:10.1080/01904167.2016.1143954.

Broyer, T. C., Carlton, A. B., Johnson, C. M., Stout, P. R. 1954. Chlorine - A micronutrient element for higher plants. Plant Physiology, 29: 526 - 532.

CID Bio-Science. 2013. CI-710 Miniature Leaf Spectrometer Operation Manual. CID BioScience Inc. Camas, Washington. URL: http://www.ictinternational.com/content/uploads/2014/03/ci710_manual.pdf 
402

403

404

405

406

407

408

409

410

411

412

413

414

415

416

417

418

419

420

421

422

423

424

425

426

Cotlove E. 1963. Determination of the true chloride content of biological fluids and tissues. II. Analysis by simple, nonisotopic methods. Analytical Chemistry, 35: $101-105$.

de Paz, J.M., Visconti, F., Chiaravalle, M., Quiñones, A. 2016. Determination of persimmon leaf chloride contents using near-infrared spectroscopy (NIRS). Analytical and Bioanalytical Chemistry 408 (13): $3537-3545$.

Fearn T. 2002. Assessing calibrations: SEP, RPD, RER and R2. NIR News, 13: 12-14.

Geilfus, C.-M. 2018. Chloride: From Nutrient to Toxicant. Plant and Cell Physiology, 59 (5): $877-886$.

Gilliam J.W. 1971. Rapid measurement of chlorine in plants materials. Soil Science Society of America Proceedings, 35: 512 - 513.

Gunst, R.F. 1983. Regression analysis with multicollinear predictor variables: definition, detection and effects. Communications in Statistics - Theory and Methods, 12: 2217 - 2260.

Guskov, A., Kern, J., Gabdulkhakov, A., Broser, M., Zouni, A., Saenger, W. 2009. Cyanobacterial photosystem II at 2.9- $\AA$ resolution and the role of quinones, lipids, channels and chloride. Nature Structural \& Molecular Biology, 16: 334 - 342.

Hörtensteiner, S., Kräutler, B. 2011. Chlorophyll breakdown in higher plants. Biochimica et Biophysica Acta-Bioenergetics, 1807 (8): 977 - 988.

Li, B., Tester, M., Gilliham, M. 2017. Chloride on the Move. Trends in Plant Science, 22 (3): $236-248$.

Marquardt, D.W. 1980. You Should Standardize the Predictor Variables in Your Regression Models, Journal of the American Statistical Association, 75: 74 - 103.

Marschner, H. 2011. Marschner's Mineral Nutrition of Higher Plants, $3^{\text {rd }}$ edn. London: Academic Press.

Miller, R.O. Extractable chloride, nitrate, orthophosphate, potassium, and sulfate-sulfur in plant tissue: $2 \%$ acetic acid extraction. In: Kalra YP, editor. Handbook of reference methods for plant analysis. Boca Raton: CRC Press; 1998. pp. 115 - 118. 
428 Padilla, F.M., Gallardo, M., Peña-Fleitas, M.T., de Souza, R., Thompson, R.T. 2018. Proximal

429 Optical Sensors for Nitrogen Management of Vegetable Crops: A Review. Sensors, 18: 2083

430 (23 pp.).

431

432

R Core Team. 2018. R: A language and environment for statistical computing. R Foundation for Statistical Computing, Vienna, Austria. URL: https://www.R-project.org/.

Raveh, E. 2005. Methods to assess potential chloride stress in citrus: Analysis of leaves, fruit, stem-xylem sap, and roots. HortTechnology, 15 (1): 104 - 108.

437

438

Raven, J.A. 2017. Chloride: Essential micronutrient and multifunctional beneficial ion. Journal of Experimental Botany, 68 (3): $359-367$.

440

Romero, L., Belakbir, A., Ragala, L., Ruiz, J.M. 1997. Response of plant yield and leaf pigments to saline conditions: Effectiveness of different rootstocks in melon plants (Cucumis melo L.). Soil Science and Plant Nutrition, 43(4), 855 - 862.

Samborski, S.M., Tremblay, Fallon, E. 2009. Strategies to make use of plant sensors-based diagnostic information for nitrogen recommendations. Agronomy Journal, 101 (4): 800 - 816.

447

448

Shao, X., Ning, Y., Liu, F., Li, J., Cai, W. 2012. Application of near-infrared spectroscopy in micro inorganic analysis. Acta Chimica Sinica, 70 (20): 2109 - 2114.

450

Taniguchi, M., Du, H., Lindsey, J.S. 2018. PhotochemCAD 3: Diverse Modules for

452 Photophysical Calculations with Multiple Spectral Databases. Photochemistry and 453 Photobiology, 94: 277-289.

454

455

Tobias, R. D. 2003. An Introduction to partial least squares regression. URL: 456 https://stats.idre.ucla.edu/wp-content/uploads/2016/02/pls.pdf. Accessed 2019/02/04.

457

van Maarschalkerweerd M, Bro, R., Egebo, M., Husted, S. 2013. Diagnosing latent copper deficiency in intact barley leaves (Hordeum vulgare, L.) using near infrared spectroscopy. Journal of Agricultural and Food Chemistry, 61: 10901-10910. 
462 Viscarra Rossel, R. 2008. ParLeS: Software for chemometric analysis of spectroscopic data.

463 Chemometrics and Intelligent Laboratory Systems, 90: 72-83.

464 Visconti, F., Intrigliolo, D.S., Quiñones, A., Tudela, L., Bonet, L., de Paz, J.M. 2017.

465 Differences in specific chloride toxicity to Diospyros kaki cv. "Rojo Brillante" grafted on D.

466 lotus and D. virginiana. Scientia Horticulturae, 214: 83-90.

467 White, P.J., Broadley, M.R., 2001. Chloride in Soils and its Uptake and Movement within the 468 Plant: A Review. Annals of Botany 88 (6), 967-988. doi:10.1006/anbo.2001.1540.

469 Wold, S., Sjöström, M., Eriksson, L. 2001. PLS-regression: a basic tool of chemometrics. 470 Chemometrics and Intelligent Laboratory Systems, 58: $109-130$.

471 Xu, G., Magen, H., Tarchitzky, J., Kafkafi, V. 2000. Advances in chloride nutrition. Advances 472 in Agronomy, 68: 96-150.

473 Zhang, S., Shen, Q., Nie, C., Huang, Y., Wang, J., Hu, Q., Ding, X., Zhou, Y., Chen, Y. 2019.

474 Hyperspectral inversion of heavy metal content in reclaimed soil from a mining wasteland based 475 on different spectral transformation and modeling methods. Spectrochimica Acta - Part A: 476 Molecular and Biomolecular Spectroscopy, 211, $393-400$.

\section{$477 \quad$ Figure captions}

478 Figure 1. Chloride contents determined in the persimmon leaves throughout time during the 479 growing season (DOY)

480 Figure 2. Foliar reflectance $(R)$, absorbance $(A)$ and first $(\mathrm{d} A / \mathrm{d} \lambda)$ and second $\left(\mathrm{d}^{2} A / \mathrm{d} \lambda^{2}\right)$ 481 derivatives of the absorbance

482 Figure 3. Pearson's product moment correlation coefficients between the reference leaf chloride 483 and the foliar reflectance $(R)$, absorbance $(A)$, first derivative of the apparent absorbance $484(\mathrm{~d} A / \mathrm{d} \lambda)$, and second derivative of the apparent absorbance $\left(\mathrm{d}^{2} A / \mathrm{d} \lambda^{2}\right)$

485 Figure 4. Absorbance spectra of the main pigments in the leaves of crop trees (Source: own 486 preparation using absorption coefficients from Taniguchi et al. (2018) and taking the following 487 percents of chlorophyll a, chlorophyll $\mathrm{b}$ and $\beta$-carotene: $62.4,19.3$ and $18.4 \%$ )

Figure 5. PLSR-predicted against observed (reference) leaf chloride in the training and testing 489 sets

490 Figure 6. Two-way influence of time throughout the growing season, i.e. day of the year (DOY) 491 on the leaf spectrum 
492 Figure 7. Plot of residuals against predicted chloride content (left) in the testing dataset, and 493 plot of expected against observed (reference) cumulative probabilities of chloride content also in 494 the testing dataset (right)

\section{Table captions}

496 Table 1. Statistical summary of the chloride contents in the persimmon leaves

497 Table 2. Summary of the Pearson's product-moment correlation coefficients (r) between the 498 leaf chloride content and the four spectral datasets

499 Table 3. Results of the leave-one-out cross-validations and external validations of the PLSR 500 models to predict leaf chloride on base the foliar reflectance, either with or without DOY, and 501 with different numbers of latent components (LCs). In italics the selected model

502

503

504

505

506

507

508

509

510

511

512

513

514

515

516 
$517 \quad$ Figure 1.

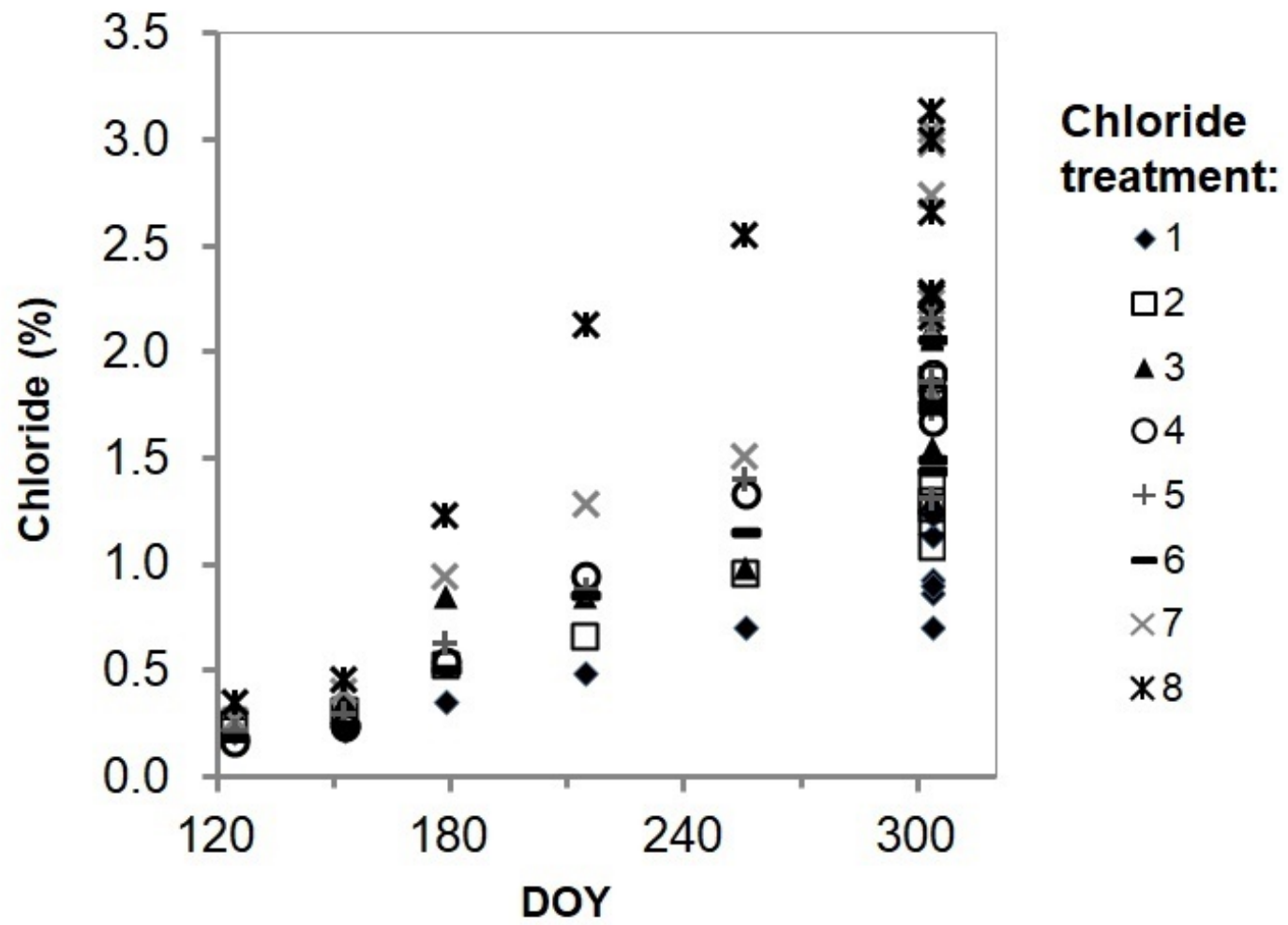

518

519

520

521

522

523

524

525

526

527

528

529

530 
$531 \quad$ Figure 2.

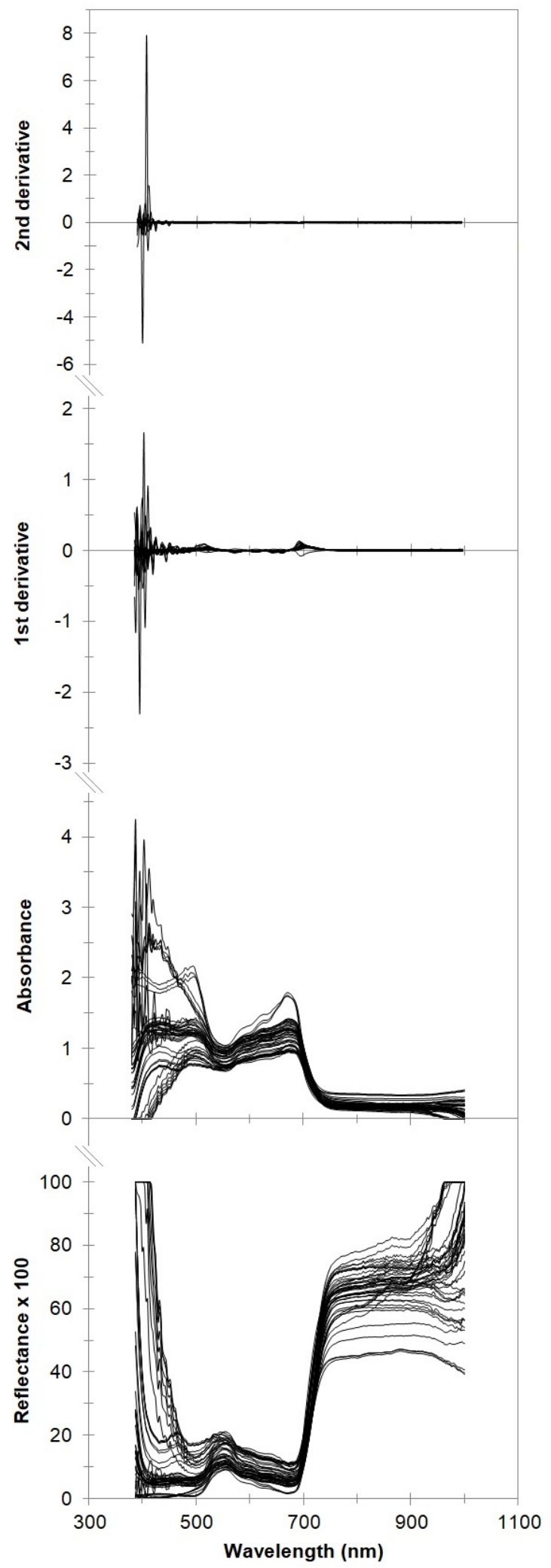

532

533 
Figure 3.
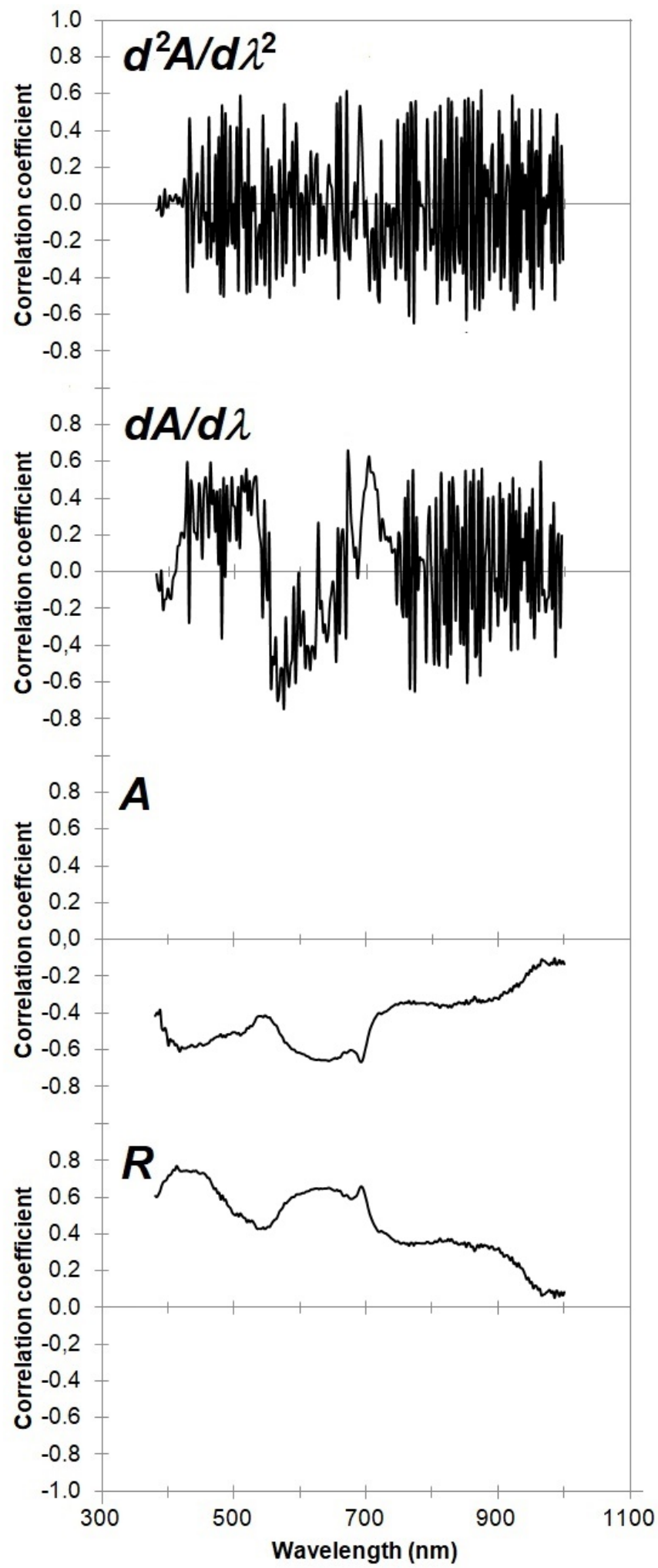

535 
$537 \quad$ Figure 4.

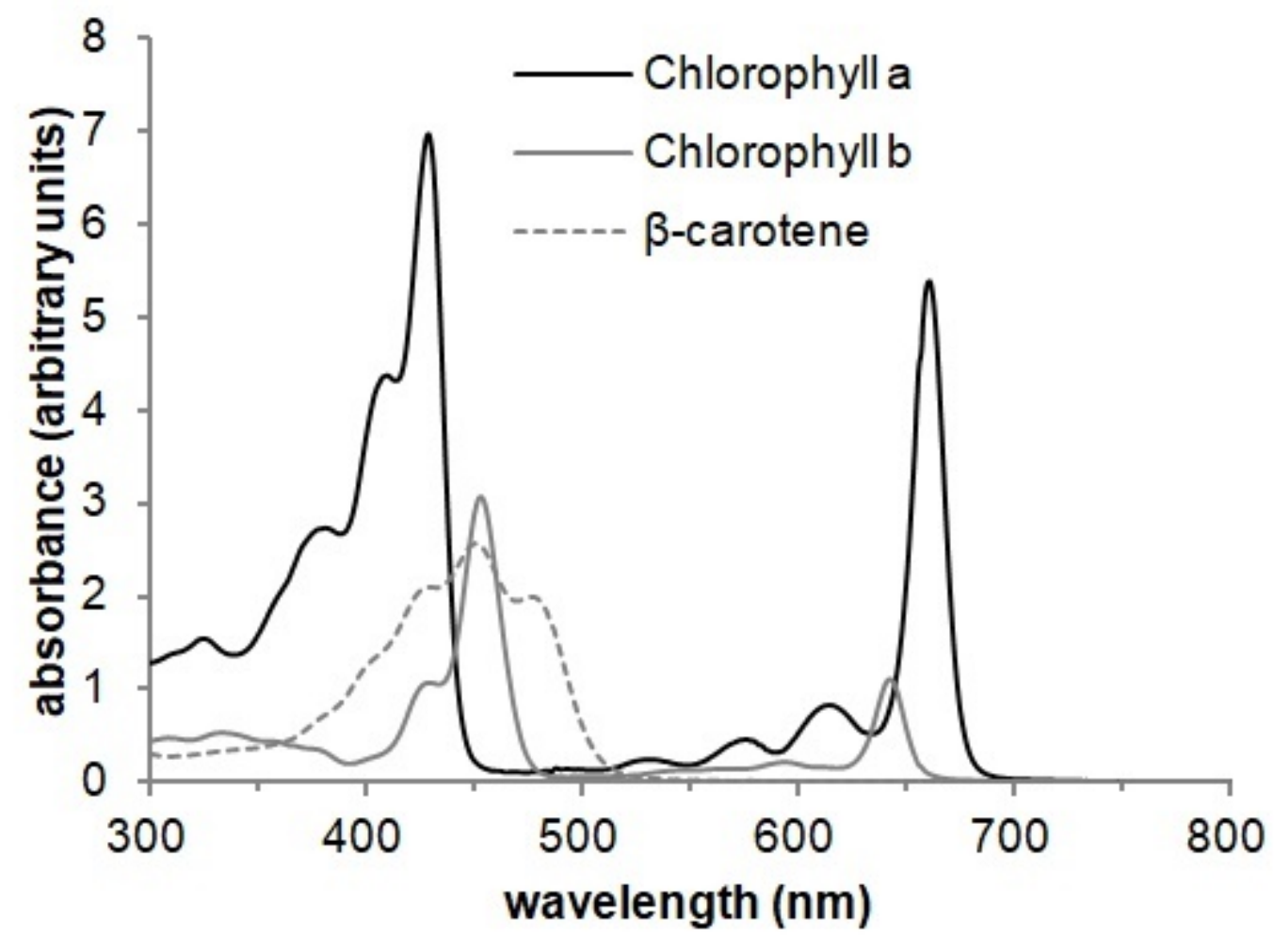

538

539

540

541

542

543

544

545

546

547

548

549

550 
552
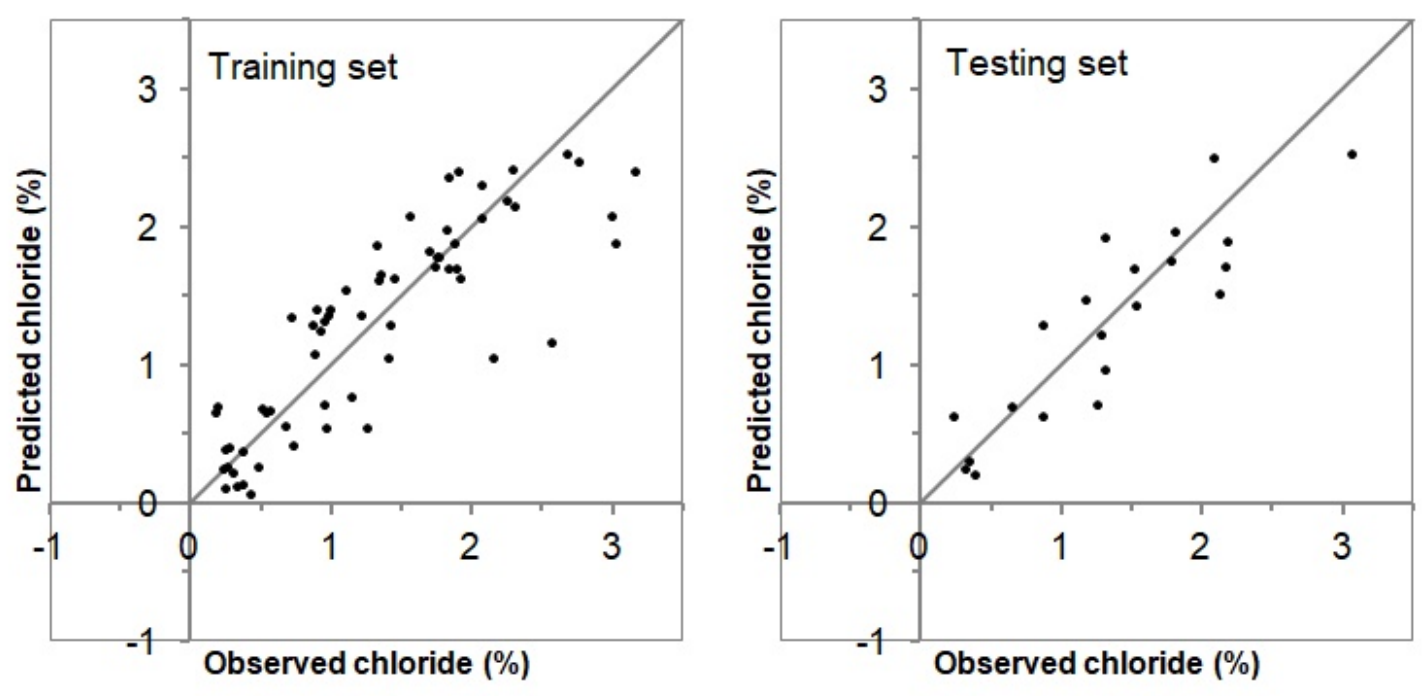

553

554

555

556

557

558

559

560

561

562

563

564

565

566

567 
Figure 6.

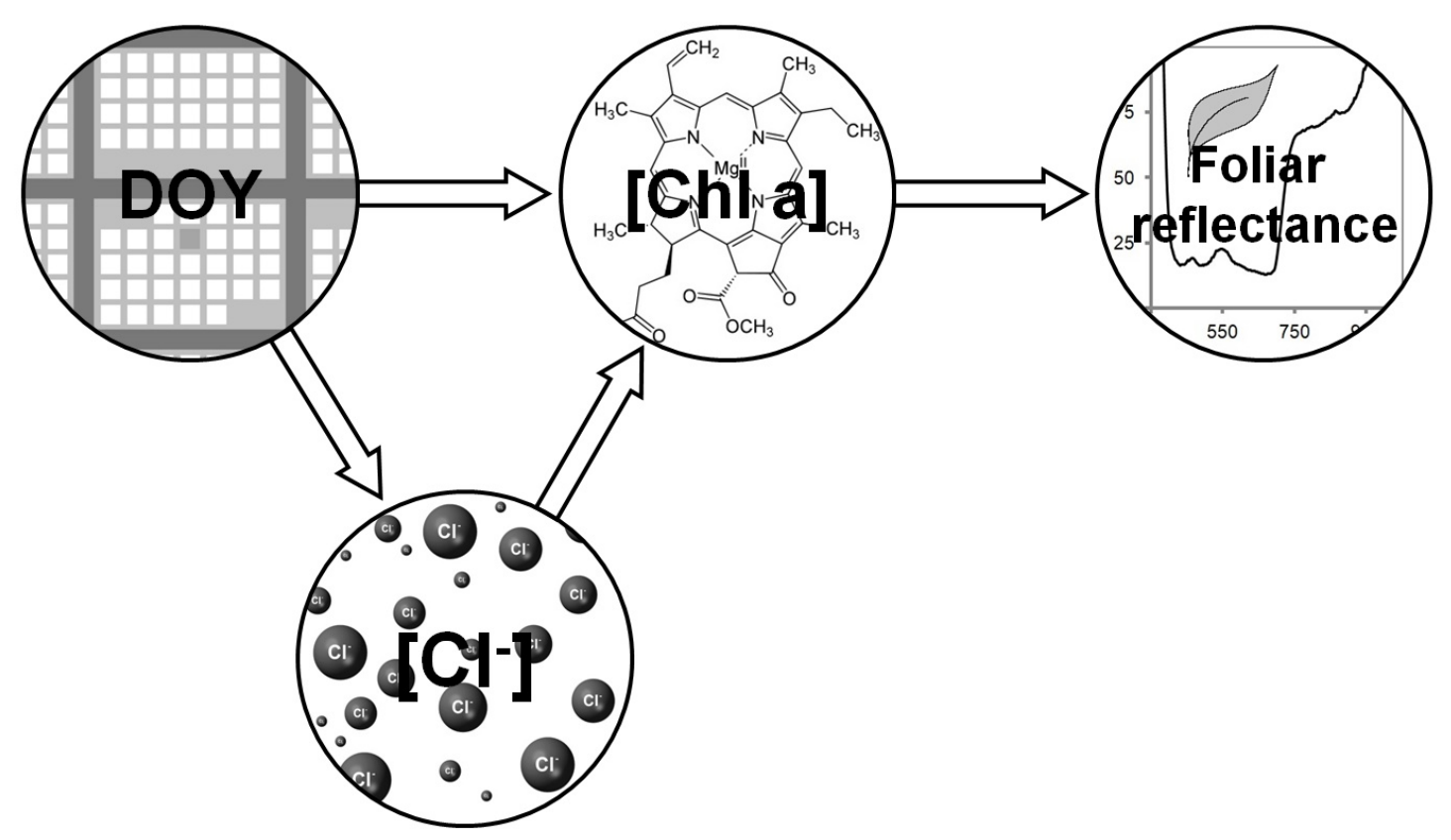

569

570

571

572

573

574

575

576

577

578

579

580

581

582 
Figure 7.

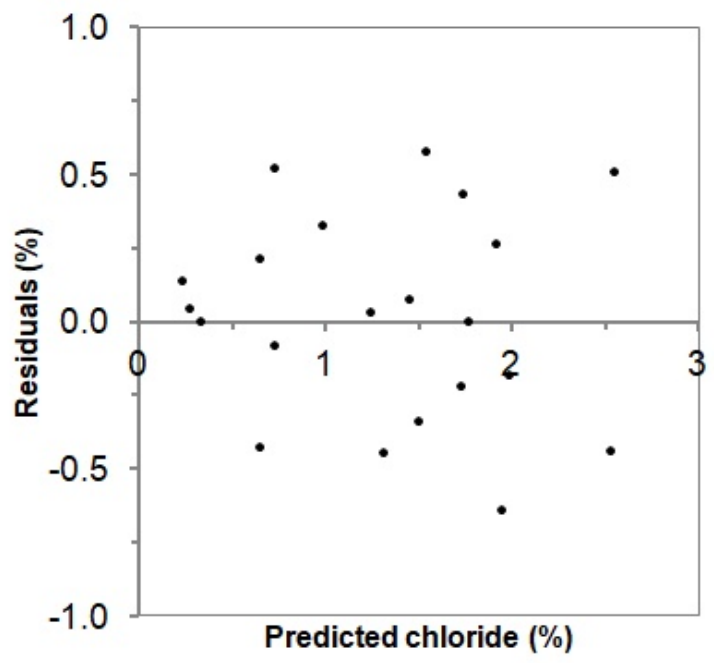

584

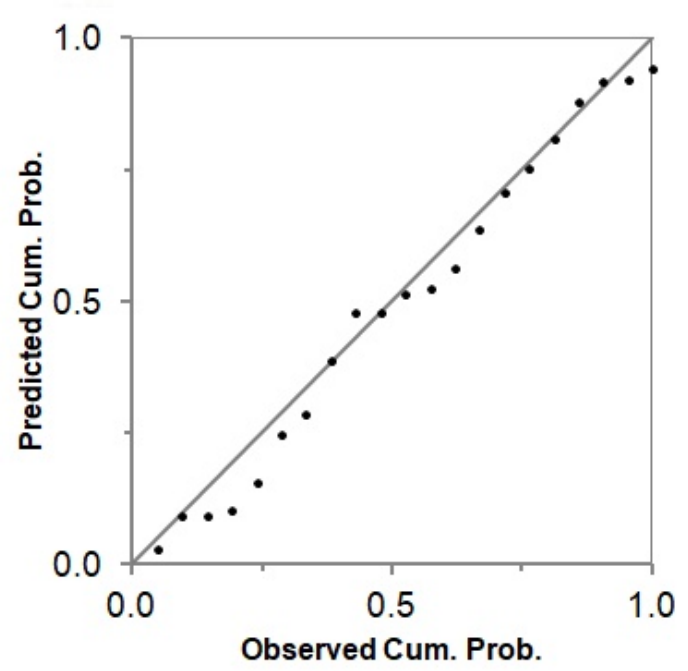

585

586

587

588

589

590

591

592

593

594

595

596

597

598

599 
Table 1.

\begin{tabular}{|l|l|l|l|}
\hline Descriptor & Complete set & Training set & Testing set \\
\hline $\mathrm{N}$ & 83 & 62 & 21 \\
\hline Mean $\left(\% \mathrm{Cl}^{-}\right)$ & 1.304 & 1.295 & 1.332 \\
\hline $\mathrm{SD}\left(\% \mathrm{Cl}^{-}\right)$ & 0.791 & 0.810 & 0.749 \\
\hline Maximum $\left(\% \mathrm{Cl}^{-}\right)$ & 3.144 & 3.144 & 3.054 \\
\hline Minimum $\left(\% \mathrm{Cl}^{-}\right)$ & 0.166 & 0.166 & 0.22 \\
\hline Skewness coefficient & 0.397 & 0.429 & 0.292 \\
\hline K-S \& Lilliefors's statistic & 0.078 & 0.100 & 0.092 \\
\hline K-S's p-value & 0.695 & 0.533 & 0.987 \\
\hline Lilliefors's p-value & 0.245 & 0.129 & 0.914 \\
\hline
\end{tabular}

601

602

603

604

605

606

607

608

609

610

611

612

613

614

615

616

617

618

619 
Table 2.

\begin{tabular}{|l|r|r|r|r|}
\hline Spectral dataset & Minimum & Maximum & $\begin{array}{r}\text { Maximum } \\
\text { absolute value }\end{array}$ & $\begin{array}{r}\text { Number of wavelengths } \\
\text { with }|\mathbf{r}| \geq \mathbf{0 . 6 5}\end{array}$ \\
\hline Reflectance $(R)$ & 0.054 & 0.772 & 0.772 & 37 \\
\hline Absorbance $(A)$ & -0.664 & -0.100 & 0.664 & 11 \\
\hline Absorbance $1^{\text {st }}$ der. $(\mathrm{d} A / \mathrm{d} \lambda)$ & -0.742 & 0.650 & 0.742 & 4 \\
\hline Absorbance $2^{\text {nd }}$ der. $\left(\mathrm{d}^{2} A / \mathrm{d} \lambda^{2}\right)$ & -0.651 & 0.620 & 0.651 & 1 \\
\hline
\end{tabular}

621

622

623

624

625

626

627

628

629

630

631

632

633

634

635

636

637

638

639

640 
Table 3.

\begin{tabular}{|c|c|c|c|c|c|c|c|}
\hline \multirow[b]{2}{*}{ DOY } & \multirow{2}{*}{$\begin{array}{l}\text { Number of } \\
\text { LCs }\end{array}$} & \multicolumn{3}{|c|}{ Cross-validation } & \multicolumn{3}{|c|}{ External validation } \\
\hline & & $\mathbf{R}^{2}$ & $\begin{array}{l}\text { RMSE } \\
\left(\% \mathrm{Cl}^{-}\right)\end{array}$ & RPD & $\mathbf{R}^{2}$ & $\begin{array}{l}\text { RMSE } \\
\left(\% I^{-}\right)\end{array}$ & RPD \\
\hline No & 6 & 0.599 & 0.51 & 1.58 & 0.679 & 0.42 & 1.80 \\
\hline No & 7 & 0.623 & 0.50 & 1.63 & 0.694 & 0.41 & 1.84 \\
\hline No & 8 & 0.642 & 0.49 & 1.66 & 0.792 & 0.34 & 2.20 \\
\hline No & 9 & 0.676 & 0.46 & 1.75 & 0.745 & 0.38 & 1.99 \\
\hline No & 10 & 0.672 & 0.47 & 1.73 & 0.738 & 0.38 & 1.95 \\
\hline No & 11 & 0.672 & 0.47 & 1.73 & 0.699 & 0.42 & 1.79 \\
\hline No & 12 & 0.667 & 0.47 & 1.71 & 0.653 & 0.46 & 1.64 \\
\hline Yes & 6 & 0.671 & 0.46 & 1.75 & 0.707 & 0.40 & 1.85 \\
\hline Yes & 7 & 0.687 & 0.45 & 1.79 & 0.751 & 0.37 & 2.03 \\
\hline Yes & 8 & 0.724 & 0.42 & 1.91 & 0.782 & 0.34 & 2.18 \\
\hline Yes & 9 & 0.707 & 0.44 & 1.84 & 0.798 & 0.33 & 2.25 \\
\hline Yes & 10 & 0.718 & 0.43 & 1.88 & 0.768 & 0.35 & 2.11 \\
\hline Yes & 11 & 0.713 & 0.44 & 1.85 & 0.731 & 0.38 & 1.95 \\
\hline Yes & 12 & 0.699 & 0.45 & 1.80 & 0.726 & 0.39 & 1.93 \\
\hline
\end{tabular}

642

643

644

645

646

647

648

649

650

651

652

653

654

655

656

657 